\title{
LAS NUEVAS TIERRAS DEL BUDA: GLOBALIZACIÓN, MEDIOS DE COMUNICACIÓN Y DESCENTRALIZACIÓN EN UNA MINORÍA RELIGIOSA DE LA ARGENTINA
}

\author{
Catón Eduardo Carini ${ }^{1}$
}

\begin{abstract}
Resumen: El artículo explora algunos factores que posibilitaron el surgimiento y desarrollo de los grupos budistas zen de la Argentina. Se centra en mostrar la capacidad de agencia de los actores individuales, los cuales construyeron canales de circulación de representaciones y prácticas de esta religión que trascienden países y continentes. Además, indaga la complementariedad entre las prácticas de convivencia territorialmente arraigadas y la utilización de los medios de comunicación a distancia más recientes que permiten articular una comunidad virtual trasnacional. Finalmente, examina el proceso de descentralización que el budismo ha vivido en la modernidad con el fin de cuestionar la noción de que la globalización de esta religión es un proceso unidireccional de Oriente a Occidente.
\end{abstract}

Palabras clave: Budismo zen - Argentina - Globalización - Medios de comunicación

Abstract: In this article I explore some factors that contributed to the emergence and development of Buddhist Zen groups in Argentina. I focus on showing the ability of the individual actors' agency, who has built channels of circulation of representations and practices of this religion that have transcended countries and continents. Also, I investigate the complementary relationship between the territorially rooted practices of coexistence and the use of the media that allows articulating a transnational virtual community. Finally, I examine the process of decentralization that the Buddhism has been through within the modern world with the purpose of questioning the notion that the globalization of this religion is an unidirectional process from East to West.

Keywords: Zen Buddhism- Argentina - globalization - the media.

\section{INTRODUCCIÓN}

La llegada del budismo a Europa, Australia y América presenta algunas características que lo distinguen de la forma en que se esparció histórica-

${ }^{1}$ Licenciado en Antropología (UNLP), Magister en Antropología Social (FLACSO), Doctorando en Antropología (UNLP), Becario del CONICET.

Debates do NER, Porto Alegre, Ano io, N. I6, P. 49-70, JUl./Dez. 2009 
mente por Asia. En los países orientales fue introducido de "arriba hacia abajo", como una religión de estado promovida por el gobierno ${ }^{2}$, en un proceso que implicó un largo período de tiempo. Por el contrario, en su relativamente reciente expansión al resto del mundo, fue introducido de "abajo hacia arriba", muchas veces por personas interesadas en la meditación y la filosofía budista que, aunque contaban con escasos recursos en términos de poder, desencadenaron un rápido desarrollo de escuelas budistas en todo el mundo (Weber, 1998; Baumann, 2002). Diversos autores han abordado este fenómeno, frecuentemente desde una perspectiva histórica y sociológica que tiene en cuenta los cambios, adaptaciones y dilemas que conllevan el establecimiento de centros budistas de distinta denominación en Europa (Baumann, 2001, 2002; Koné, 2001; Obadia, 2001), Norteamérica (Preston, 1988; Numrich, 1996; Lachs, 1999; Padget, 2000; Hughes Seager, 2002; Mullen, 2004), Canadá (Mathews, 2002), y Australia (Trembath, 1996; Spuler, 2002) ${ }^{3}$. Por otra parte, los estudios en América Latina son escasos -en Argentina sólo recientemente se ha comenzado a explorar el fenómeno del budismo local desde la perspectiva de la ciencias sociales (cf. Carini, 2005, 2006, 2007, 2009) ${ }^{4}$-, aunque una excepción es el caso de Brasil, en donde varios investigadores han indagado el tema que aquí nos ocupa (e.g., Alves, 2006; Madalena Genz, 2005; Pereira, 2002, 2007; Rocha, 2000, 2001; Shoji, 2002, 2006; Usarski, 2002, 2006).

Con el fin de aportar al conocimiento del proceso de dispersión del Budismo en Occidente -y al estudio de una de las minorias menos investigadas del campo religioso argentino-, en este articulo me propongo analizar algunos factores que han posibilitado la aparición, el desarrollo y la conti-

${ }^{2} \mathrm{Y}$, como señala Weber, con el fin de "domesticar a los súbditos" y aprovechar el conocimiento de la escritura por parte de los monjes para organizar la administración del estado (Weber, 1998, p. 270-303).

3 También se han realizado trabajos más generales sobre el budismo en Occidente (e.g. Coleman, 2001; Freiberger, 2001; Wallace, 2002).

${ }^{4}$ También es posible encontrar alguna información sobre grupos budistas -aunque no de la escuela zen- en trabajos generales sobre el campo religioso argentino (cf. Mallimaci, 2003; Bianchi, 2004).

Debates do NER, Porto Alegre, Ano io, N. I6, P. 49-70, Jul./Dez. 2009 
nuidad de grupos budistas zen locales. Para ello, en primer lugar exploraré la forma en que estos enfrentan algunas tensiones y dilemas propios de su condición transnacional mediante prácticas vinculadas con el empleo de nuevas tecnologías de comunicación a distancia. En segundo lugar, me centraré en la otra cara de la globalización del budismo zen -i.e. el proceso de localización, esencial para la viabilidad de sus comunidades- mediante un ejemplo de prácticas territorialmente arraigadas en las cuales, como veremos, son centrales las relaciones intercorporales dentro de un espacio concreto, estructurado en gran medida ritualmente. En tercer lugar, indagaré en los vínculos que se establecen entre los grupos estudiados, especialmente en los motivos por los cuales se erigen fronteras simbólicas entre los mismos. Y por último, a la luz de la discusión anterior y de considerar las transformaciones que el campo budista japonés ha vivido en la modernidad, reflexionaré sobre las características más conspicuas del budismo zen argentino -y por extensión, del zen occidental- especialmente las vinculadas con el proceso de globalización, localización y descentralización.

Pero antes, efectuaremos una breve reseña de los grupos zen de la Argentina, a fin de brindar los mínimos elementos empíricos que permitan contextualizar nuestra discusión ${ }^{5}$. En este sentido, existen tres vías principales de entrada del budismo en los países occidentales. Primero, mediante instituciones ligadas a migraciones asiáticas. Segundo, a través de maestros misioneros de origen oriental. Y tercero, por maestros occidentales que aprendieron, ya sea en cualquiera de los dos contextos anteriores, o en los países donde esta religión se encuentra arraigada desde hace siglos.

Con respecto a la primera vía de entrada, si bien la llegada del budismo vinculada a maestros e instituciones ligados a diásporas orientales ha cumplido un rol importante en la dispersión del budismo en Occidente -especialmente para el caso del budismo chino, el coreano y el vietnamita, difundidos principalmente debido a migraciones globales (Beyer, 1998)-,

\footnotetext{
${ }^{5}$ En otras partes hemos descripto con mayor profundidad las principales características de los grupos zen de la Argentina -su historia, rituales, representaciones y el perfil sociocultural de sus miembros, entre otras cuestiones- aquí no nos detendremos en ello por cuestiones de espacio (cfr. Carini 2005, 2006, 2007, 2009).
}

Debates do NER, Porto Alegre, ano io, N. I6, P. 49-70, JUl./Dez. 2009 
el budismo zen en gran parte del mundo no tiene un origen étnico, salvo el caso de Brasil, donde ha sido fundamental la colectividad japonesa en el establecimiento de esta religión (Rocha, 2000, 2001). En el caso de Argentina, los inmigrantes japoneses que vinieron a este país no trajeron el budismo zen como parte de su bagaje cultural, ya que aquellos en su mayoría o bien se convirtieron al cristianismo o pertenecían originariamente a la escuela budista Jodo Shinshu (Mallimaci, 2003). En suma, en la Argentina el público zen está compuesto casi exclusivamente de conversos sin antepasados orientales y la movilidad de individuos o familias japonesas no cumplió ningún rol en la difusión del zen en el país.

Como dijimos, la segunda vía de entrada del budismo es través de maestros que realizaron actividades misioneras, teniendo como objetivo un público occidental. La importancia de las misiones budistas -encabezadas por algún líder carismático- en el establecimiento del zen fuera de Asia ha sido destacada por numerosos investigadores (cfr. Preston, 1988; Obadia, 2001; Beyer, 1998; Koné, 2001; McMahan, 2002). En el contexto local dos maestros japoneses desempeñaron actividades de difusión del zen. Uno de ellos es Ryotan Tokuda, quien llegó a Brasil en 1968 para dirigir un templo de inmigrantes japoneses. Tokuda se destacó por abrir las puertas de aquel a los brasileños no japoneses y por difundir el zen por todo el país, más allá del ámbito de la colectividad. Este maestro comenzó sus visitas a la Argentina en 1984 y vivió un tiempo en Buenos Aires a mediados de los ochenta. Sin embargo, luego de un tiempo dejó de venir al país y su misión se interrumpió. Otro centro zen -hoy disuelto- relacionado a la actividad misionera de un monje japonés es el Dojo del Árbol. Éste grupo funcionó en la Argentina en la década de los noventa (luego se disolvió) y fue dirigido por el maestro japonés Daigyo Moriyama y su discípula francesa, Joshin Bachoux ${ }^{7}$.

De modo que la línea de entrada del zen a través de monjes japoneses misioneros quedó trunca, a diferencia de otros lugares, como Estados

${ }^{6}$ Dojo: lugar donde se practica la meditación zen.

${ }^{7}$ Ver Madalena Genz (2005) para un estudio antropológico de la misión de Moriyama en Brasil.

Debates do NER, Porto Alegre, ano io, N. I6, P. 49-70, JUl./Dez. 2009 
Unidos y Europa, donde fue muy importante. De todos modos, muchos de los practicantes y maestros actuales comenzaron su camino en el zen con Tokuda, por lo cual es necesario considerar esta primera experiencia como un hito que marcó rumbos y cristalizó vocaciones que luego fueron retomadas en otros contextos. Esto nos lleva directamente a la tercera línea de entrada, la representada por maestros occidentales que enseñan zen tanto en sus propios países como en el exterior. Para el caso de Argentina, podemos distinguir, por un lado, a los maestros nativos y, por el otro, a los misioneros no japoneses.

Con respecto a la primera subdivisión, algunos grupos zen fueron creados desde mediados de los años ochenta debido a que algunos argentinos viajaron al exterior para estudiar budismo zen con reconocidos maestros internacionales y luego volvieron al país donde formaron grupos locales. Uno de ellos es Jorge Bustamante, quien actualmente es un maestro de reconocida trayectoria en el país y fundador del grupo La Ermita de Paja. Otro es Ricardo Dokyu, un maestro argentino, que dirige un grupo de práctica de meditación -Templo Serena Alegría- en la Ciudad de Buenos Aires, y es el representante de la sede oficial del zen soto (la sotoshu) en Latinoamérica.

Además podemos rastrear la influencia seminal de Tokuda es el Dojo del Jardín, pues una de las personas que comenzó a practicar zen con este maestro, Aurora Oshiro, gestionó un espacio en el Jardín Japonés para realizar meditación. El grupo se empezó a articular en dicho espacio a partir de 1987, y con el tiempo fue sumando practicantes. Sin embargo, Oshiro fue enviada a misionar a Perú luego de pasar un tiempo en Japón, y el grupo local cesó de funcionar en el año 2006.

Por otra parte, existen dos casos de maestros que enseñan en Argentina que, a diferencia de los anteriores, se han formado en el zen norteamericano. El primero es el del sacerdote budista Seizan Feijoo (de la línea del zen rinzai) y el otro es el de de Augusto Alcalde, el fundador de la Sangha Vimalakirti (este grupo, hoy disuelto, estuvo vinculado con la Diamond Sangha estadounidense).

Más allá de los centros zen desarrollados en torno a maestros argentinos,

Debates do NER, Porto Alegre, Ano io, N. I6, P. 49-70, JUl./Dez. 2009 
existen tres dirigidos por maestros extranjeros occidentales: el Zendo ${ }^{8}$ Betania, encabezado por Pedro Flores, cuya sede principal se encuentra ubicada en España; el Grupo Zen Viento del Sur, dirigido por Daniel Terragno, un maestro de origen chileno que reside desde hace más de cuarenta años en Estados Unidos; y la Asociación Zen de América Latina, liderada por un maestro francés llamado Stéphane Thibaut, antiguo discípulo de Taisen Deshimaru, quien enseña en Francia y Latinoamérica.

\section{NUEVOS MEDIOS DE COMUNICACIÓN Y AGENCIA EN EL PROCESO DE TRANSNACIONALIACIÓN DEL BUDISMO ZEN}

Luego de este breve recorrido por los grupos zen argentinos, me interesa señalar que la emergencia de comunidades budistas en la Argentina tiene como condiciones de posibilidad una serie de factores sociales, tecnológicos y culturales complejos, tres de los cuales explicitaré a continuación.

Primero, las transformaciones en los medios de comunicación del último siglo -especialmente las relacionadas a la popularización del libro y a las prácticas de lectura' - que posibilitaron la circulación de material escrito sobre el zen en nuevos contextos, lo cual generó un ámbito propicio de interés y curiosidad hacia esta filosofía oriental en círculos intelectuales occidentales, en la contracultura norteamericana y en movimientos sociorreligiosos diversos pero estrechamente relacionados, como la Nueva Era (Carozzi, 2000) y el esoterismo (Carvalho, 1998; Velho, 1998) ${ }^{10}$.

Segundo, las prácticas de actores locales que activamente construyeron redes o canales de circulación de personas, ideas, textos y prácticas, y que

${ }^{8}$ Zendo: al igual que el término "dojo", se refiere al lugar en donde se practica la meditación zen.

${ }^{9}$ En esto sigo de cerca los planteamientos de Anderson (1983) sobre el rol del libro como medio de generar "comunidades imaginadas".

${ }^{10}$ Por otra parte, si bien esta primera recepción textual es fundamental en la popularización de las ideas zen, se encuentra marcada por un sesgo "orientalista" (Said, 2002) y descontextualizado (cfr. Baumann, 2001; Koné, 2001; McMahan, 2002). Abordamos algunas implicancias de esta problemática en el marco del zen argentino en Carini (2009).

Debates do NER, Porto Alegre, ano io, N. I6, P. 49-70, Jul./Dez. 2009 
posibilitaron el surgimiento de los grupos actuales. Los mismos conectan la Argentina con centros de enseñanza y práctica del zen en Europa, Estados Unidos, Japón y Brasil, y se fueron configurando en base al interés de algunos argentinos por una religión oriental ausente en el país.

Aquí podemos distinguir dos movimientos. Por un lado, el de actores locales que utilizan sus recursos económicos y sociales para contactar e invitar a la Argentina a maestros zen extranjeros, con el objetivo de importar su enseñanza. Los mismos se convierten en nexos claves entre el maestro extranjero y sus discípulos locales. Aquel delega en ellos la responsabilidad de organizar y la autoridad para dirigir el grupo durante gran parte del año, de modo que gracias a sus esfuerzos son posibles los centros zen transnacionales. Además, es preciso mencionar el rol que juega en lo anterior la concepción de autoridad propia del zen, pues no cualquiera puede enseñar, sino alguien consagrado por instituciones legítimamente reconocidas como aptas para hacerlo. Entonces, a medida que las comunidades se van formando, aumenta su necesidad de florecer en conexión con centros legítimos de aprendizaje y sus agentes. Los maestros extranjeros proveen modelos de comunidades de práctica"11 "auténticas", a través de la transmisión, no solo de las nociones zen, sino de un complejo cultural budista que incluye meditaciones, rituales, ceremonias, formas de alimentación, vestimenta y demás. Y el segundo movimiento es el de los argentinos que, habiéndose formado en los centros legítimos de aprendizaje, vuelven a su país para enseñar. El momento de partida comienza con un buscador espiritual en viaje al centro mítico de la sabiduría antigua, y termina con el retorno del "monje misionero". Ya no se vuelve como se partió, sino como un nativo de aquel lugar legítimo de formación y aprendizaje que retorna a su lugar de origen como profeta en su propia tierra.

${ }^{11}$ Empleamos la expresión "comunidades de práctica" en el sentido que le otorga Strauss (2000), entendiendo las prácticas como medios de construir relaciones sociales que cruzan culturas y naciones; las prácticas son "modos de estar en el mundo" que proveen las bases de estas comunidades. En este sentido, el elemento central en la articulación de la identidad colectiva no es la adhesión a un conjunto de creencias, sino la identificación con determinadas tecnologías espirituales que requieren una práctica corporal específica -como el yoga o la meditación.

Debates do NER, Porto Alegre, Ano io, N. I6, P. 49-70, Jul./Dez. 2009 
Y en estrecha relación con lo anterior se encuentra el tercer factor: el interés de los maestros extranjeros en territorios propicios para esparcir su enseñanza. En Europa y Estados Unidos existe -al menos desde la percepción nativa- un superávit de maestros y organizaciones zen, lo cual limita las posibilidades de expansión de éstos debido a la alta competencia existente en el campo religioso budista. Entonces, nuevos lugares que carecen de líderes consagrados son vistos como promisorios por los maestros zen extranjeros.

De modo que podemos decir, siguiendo a Mato (2001), que la globalización del zen es un proceso articulado en torno a las prácticas concretas de actores locales y extranjeros, más que la consecuencia de una difusión o transnacionalización religiosa impersonal y unidireccional. Esto nos lleva a alejarnos de enfoques estructurales y difusionistas que no tienen en cuenta la capacidad de agencia de los sujetos para modificar e interactuar creativamente con su entorno.

Las circunstancias mencionadas contribuyeron al proceso de emergencia de sanghas ${ }^{12}$ internacionales de budistas zen. Este tipo de comunidad es históricamente única dentro de la tradición budista, y si bien representa nuevas posibilidades - por ejemplo la creación de contextos de práctica del zen que trascienden territorio e identidades nacionales, otorgando una gran riqueza cultural y social a la experiencia de "ser zen"- también presenta nuevos problemas, que se pueden agrupar en torno preguntas: ¿Cómo generar coherencia en el grupo cuando sus miembros son pocos y están dispersos en todo el mundo? ¿Cómo enfrentar el hecho de que el budismo, y especialmente el budismo zen, requiere la presencia y guía constante de un maestro autorizado? Diversas respuestas han surgido como soluciones creativas a los dilemas planteados: cuando las relaciones interpersonales e intercorporales -i.e. cara a cara- no son posibles, debido a la fragmentación y dispersión de las comunidades zen que trascienden fronteras nacionales, las nuevas tecnologías de interacción social a distancia las reemplazan con relaciones virtuales, textuales o audiovisuales.

12 Sangha: comunidad budista compuesta por los monjes y los laicos que siguen a un maestro.

Debates do NER, Porto Alegre, ano io, N. I6, P. 49-70, JUl./Dez. 2009 
Para ilustrar este punto, señalaremos a continuación el caso del sitio web de la Asociación Zen de América Latina. En el mismo es posible leer las enseñanzas del maestro, conocer la ubicación de todos los dojos de la sangha (dispersos en Europa y América), contemplar las fotos de los Campos de Verano ${ }^{13}$, y también interactuar con el maestro planteando preguntas. Además, en el espacio virtual se encuentran publicadas las enseñanzas del maestro. Las mismas pueden ser transcripciones de enseñanzas orales o registros audiovisuales de entrevistas o conferencias. Esta enseñanza es leída -o reproducida, dependiendo del medio- en el marco de los pequeños grupos locales de la Asociación Zen de América Latina, dispersos en Argentina y en otros países.

Podemos observar, entonces, que la comunidad zen se construye, promueve y sustenta a nivel global en gran parte a través de las nuevas tecnologías de comunicación. Las fotos son narraciones de vidas posibles, que pueden convertirse en disparadores del deseo de los visitantes del sitio de probar esa experiencia, de aventurarse y pasar un Campo de Verano en el templo. Los "paisajes mediáticos" (Appadurai, 2001, p. 45) que se construyen en el sitio web no presentan un mundo quimérico, sino que son una puerta de entrada a un mundo imaginado pero real, construido y localizado. A su vez son, como diría Appadurai (2005, p. 125) "dispositivos para acortar distancias" en sanghas globalizadas.

En fin, toda esta documentación -fotos, textos y videos-, más allá de su rol estratégico como difusoras del grupo o como sustituto de la presencia corporal del maestro, es un proyecto colectivo, vinculado tanto más con una aspiración que con un recuerdo: la aspiración de visibilizar una "comunidad imaginada" (Anderson, 1983). El acto de archivar que implica la creación del sitio web, encuentra su lógica como, parafraseando a Appadurai (2005, p. 127), una creación "ex profeso para la producción de memorias anticipa-

\footnotetext{
${ }^{13}$ Encuentro de meditación de un mes de duración en donde se congrega la sangha hispanohablante del maestroThibaut, junto a algunos de sus discípulos europeos. La reunión se realiza en la falda del cerro Uritorco (Provincia de Córdoba, Argentina) donde está ubicado el templo Shobogenji. En las fotos se muestra a la gente trabajando, meditando, haciendo la comida o compartiendo un mate y una charla en el bello entorno del lugar.
}

Debates do NER, Porto Alegre, Ano io, N. I6, P. 49-70, JUl./Dez. 2009 
das por comunidades intencionales". De modo que podemos decir que los nuevos medios electrónicos posibilitan una mayor variabilidad en el stock de mundos posibles de identidades religiosas.

\section{PRÁCTICAS LOCALIZADAS, LA CONTRAPARTE DE LA GLOBALIZACIÓN}

Sin embargo, aunque el empleo de medios tecnológicos innovadores es importante para mantener la cohesión y la identidad de una comunidad zen -y para visibilizar a la misma en el marco del campo religioso argentino-, también presenta algunos problemas. Y aquí sigo los planteos de Hubert Dreyfus (2001), quien explora la forma en que la telepresencia afecta las relaciones interpersonales, generando un menor sentido de la realidad, debido a que éste depende de la presencia incorporada ${ }^{14}$.

Por ello es tan importante en el zen -y sobre todo en las comunidades lideradas por maestros extranjeros-, la participación en las instancias de encuentro interpersonal y de vida comunitaria, las cuales son el verdadero fundamento de la identidad grupal, del reconocimiento de los miembros de un centro zen como tales, tanto por ellos mismos como por los demás. En este sentido, planteo que las prácticas de comunicación global se encuentran estrechamente imbricadas con prácticas locales muy marcadas, de modo tal que no se puede entender unas sin las otras. Lo localmente arraigado, lo territorial, aunque sea estacional, es la otra cara de la globalización y la desterritorialización del zen.

El templo que la Asociación Zen de América Latina posee en Capilla del Monte brinda un claro testimonio de lo dicho anteriormente. El mismo es percibido por los miembros del grupo como algo valioso, que les pertenece a todos y construido con el esfuerzo de muchos de los que están allí. La energía material y afectiva que implicó su construcción lo sitúa como un claro

${ }^{14}$ Empleo el término "incorporada" en un sentido similar al vocablo inglés "embodied", i.e., en este caso "presencia incorporada", en tanto presencia "cara a cara", se opone a "telepresencia".

Debates do NER, Porto Alegre, ano io, N. I6, P. 49-70, JUl./Dez. 2009 
ejemplo de la "producción del lugar", de un espacio altamente significativo, base material de emociones, tradiciones y relaciones sociales activas.

El uso principal del templo es realizar allí los Campos de Verano, que encuentran su origen en una tradición milenaria. Se dice que en la época del Buda sus discípulos viajaban por todo el país durante la mayor parte del año, pero en la estación de las lluvias, cuando era difícil trasladarse, se congregaban durante tres meses en algún lugar -generalmente prestado por algún simpatizante rico - para hacer meditación juntos y escuchar las enseñanzas de su maestro. Estas representaciones actúan como dispositivos de generación de una comunidad local emergente. Muchos de los miembros de la Asociación Zen de América Latina realmente viven el Campo de Verano como la actualización de una comunidad utópica similar a la sangha del Buda. De este modo, la identidad grupal se ve reforzada por los relatos que conectan la práctica actual con la de los tiempos antiguos, creando un efecto de autenticidad.

Además, Shobogenji es un lugar de encuentro de significados y de personas que trasciende la mera localidad. Recuerdo un día -la primera vez que realicé un Campo de Verano en el año 2001- en que ocho personas estábamos realizando la tarea de clavar unos postes en el piso, con el fin de emplazar un alambrado alrededor del "Ojo de Agua", el lugar donde brota la vertiente que cruzaba el valle. Ese día estábamos todos abocados a esta tarea, y en un momento de charla y descanso alguien observó que proveníamos todos de distintos países -confieso que hasta ese momento no había notado este hecho-: un uruguayo, un francés, un español, un chileno, un colombiano, un canadiense, un mexicano, y yo, el único argentino. Surgió en mí el interrogante de qué era lo que había llevado a estas personas de todos los rincones del mundo a este momento de cruce y encuentro, a estar juntos cavando un pozo: ¿por qué, a pesar de la heterogeneidad nacional, lingüística y étnica, estas personas estaban unidas entre sí? Creo que uno de los motivos es que compartían un mundo en común -toda la cosmovisión y la práctica zen- el cual tenía la fuerza suficiente para crear un habitat de significados -el templo- que se constituía en la base material y simbólica de una comunidad de práctica fuertemente cohesionada.

Debates do NER, Porto Alegre, Ano io, N. I6, P. 49-70, JUl./Dez. 2009 
De modo que podemos considerar al templo un lugar pleno de significado, localizado y territorialmente arraigado, que refuerza periódicamente las relaciones intersubjetivas entre los miembros de la comunidad zen y promueve la constitución de una identidad colectiva que trasciende fronteras nacionales, lingüísticas y culturales.

\section{FRONTERAS SIMBÓLICAS LOCALES Y PUENTES TRANSNACIONALES}

La diversidad de escuelas budistas -que en Asia se encuentran acotadas regionalmente-, luego de su expansión al Occidente conviven juntas en el marco de un mismo país o una misma ciudad (Baumann y Prebish, 2002). De modo que la "compresión del espacio" (Harvey, 1989) característica de un mundo globalizado posibilita que haya una gran variedad de estilos de zen en una metrópoli como Buenos Aires. Incluso en un mismo barrio de esta capital puede haber un grupo de práctica zen, un templo coreano y un monasterio de budismo chino: enclaves budistas vecinos en la Argentina, que en Asia se encuentran separados por miles de kilómetros. Como señala Hannerz (1996, p. 54), "lo que se ha mantenido separado - grupos, lugares, culturas, géneros - es de alguna manera reunido" en el mundo moderno.

Esta situación -específica del budismo occidental-, según ciertos estudiosos promueve la cooperación y el mutuo reconocimiento en mayor grado que en contextos orientales, hablándose incluso de un "ecumenismo budista" (Baumann y Prebish, 2002, p. 4). En la misma línea, Cristina Rocha (2001) sugiere que el budismo en Brasil es una práctica de bricolage, pues existe un gran intercambio y circulación de miembros por escuelas y tradiciones budistas, y no se requiere lealtad a un grupo determinado.

Ahora bien, en este punto surge como primer interrogante cuál es la situación en la Argentina. Según mi experiencia de campo -e incluso la percepción nativa de muchos practicantes zen-, el cruce, el encuentro y la articulación entre los grupos budistas argentinos es poco frecuente. A pesar de la cercanía espacial, importan más las afinidades y lealtades a un

Debates do NER, Porto Alegre, ano io, N. I6, P. 49-70, JUl./Dez. 2009 
maestro o una comunidad de práctica que las distancias geográficas. El tránsito de practicantes entre diferentes centros zen de hecho existe, pero de forma no oficial, soslayada. En este contexto, las fronteras simbólicas entre los diferentes grupos son más importantes que las que existen entre territorios y países.

Consiguientemente, una segunda pregunta que nos planteamos es por qué se establecen aquellas. Considero que uno de los factores radica en que la producción de la identidad colectiva se articula en torno a la apropiación de un pasado mítico que remonta la autenticidad del grupo -y, sobre todo de su tótem, el maestro zen- a un linaje de ancestros o patriarcas. Como cada maestro tiene su filiación religiosa particular, muchas veces la búsqueda de la legitimidad de la propia comunidad de práctica tiene por efecto secundario la deslegitimación de las demás. Esto se evidencia, por ejemplo, en las conversaciones ocasionales en las cuales los miembros de un grupo hablan de las diferencias entre sus prácticas -e.g. rituales, técnicas de meditación, formas de autentificar un maestro, permisividad en las reglas de convivencia-, y las de los otros centros, donde se valora positivamente el ethos propio al mismo tiempo que se evalúa críticamente el de los demás.

Cuando un grupo zen se encuentra abocado a la tarea de reinventar una comunidad religiosa plausible dentro del marco occidental, se ve implicado en la doble meta de la modernidad que plantea Geertz (1973): crear una práctica tradicionalmente auténtica y, a la vez, acorde con el contexto sociocultural del siglo XXI. Por ello no son simplemente conservadores o innovadores en sus prácticas o representaciones, sino que son, en términos de Tarducci (2000, p. 186) "selectivamente modernos y selectivamente tradicionalistas". No vamos a profundizar aquí en qué aspectos cada centro zen salvaguarda, transforma o simplemente ignora de las prácticas tradicionales - un proceso no exento de dilemas, tensiones y ambigüedades, que avanza más por ensayo y error que por una planificación metódica.

Pero sí es necesario al menos mencionar dos cuestiones. Primero, que cierta ambigüedad atraviesa este fenómeno, pues las adaptaciones adquieren muchas veces un cariz restaurador -obviamente relacionado con la cuestión de la legitimidad- por lo cual la reforma es considerada como un retorno

Debates do NER, Porto Alegre, Ano io, N. I6, P. 49-70, JUl./Dez. 2009 
a prácticas que hacen a la esencia del zen, dejadas de lado por los monjes japoneses. Entonces, más que algo nuevo, las adaptaciones a la tradición muchas veces son algo así como innovaciones tradicionalistas. Y segundo, que una consecuencia de esto es la racionalización de las ventajas de las propias elecciones en la adaptación efectuada, lo cual, frecuentemente, conlleva argumentos negativos sobre las elecciones de los otros grupos.

En otras palabras, la búsqueda de autenticidad como dispositivo de producción de una comunidad legítima, genera muy a menudo el establecimiento de barreras simbólicas entre los grupos zen. Además, este proceso se ve favorecido porque aquellos son pocos, generalmente no se conocen mucho entre sí y su historia es reciente. Lo contrario sucede en otros países occidentales, donde la mayor densidad y trayectoria del budismo en estos lugares promueve el encuentro, el diálogo y el reconocimiento del otro.

\section{REFLEXIONES FINALES: MODERNIDAD, GLOBALIZACIÓN Y DESCENTRALIZACIÓN EN EL BUDISMO JAPONÉS}

En base a las trayectorias de vida de los maestros zen que enseñan o enseñaron en la Argentina, podemos afirmar que Japón es un referente importante a la hora de la formación de un líder legítimo. Joshin Bachoux, Jorge Bustamante, Ricardo Dokyu y Aurora Oshiro -y muchos discípulos de esta última- fueron al país oriental en busca de la tradición original, luego de sus primeras experiencias en Francia -los dos primeros-, y en Argentina o Brasil -los dos últimos. Bustamante afirmaba (en una entrevista que le realizamos), que no estaba de acuerdo con algunas adaptaciones al zen practicadas en Francia por considerarlas muy permisivas. De forma similar, Tokuda le recomendó a Dokyu que fuera a Japón a formarse en el zen cuando éste estaba aprendiendo dicha disciplina oriental en Brasil. Estas y otras trayectorias de personas que empiezan a practicar en Occidente y terminan su formación en Japón se vinculan con la cuestión de la autenticidad como valor de consumo. El haber estudiado zen en un templo japonés posiblemente contribuyó a otorgarle un alto grado de legitimidad a la religión que estos maestros argentinos difunden en la Argentina.

Debates do NER, Porto Alegre, ano io, N. I6, P. 49-70, JUl./Dez. 2009 
No obstante, la dispersión del budismo no es la sencilla transposición de un conjunto de prácticas y representaciones desde un centro asiático hacia una periferia occidental: la aparición de nuevos centros legítimos de aprendizaje evidencian un proceso de descentralización en esta religión ${ }^{15}$. Varios maestros zen se formaron en países distintos que Japón: los argentinos Seizan Feijoo y Augusto Alcalde aprendieron en Norteamérica, y Pedro Flores, Daniel Terragno y Stéphane Thibaut, en España, Estados Unidos y Francia, respectivamente. De modo que, tanto el zen como otras denominaciones religiosas orientales -e.g. el hinduismo-, se han convertido en religiones multicentradas, ya no identificada con una cultura o un país particular (Beyer, 1998).

Más aún, la comprensión de las raíces del proceso de globalización y descentralización del zen debe ser entendida en el marco del impacto que la modernidad ha tenido en el budismo japonés durante los últimos ciento cincuenta años ${ }^{16}$. A partir del período Meiji (1868-1912) surgió en Japón una corriente budista crítica y reformista que intenta alinear esta religión con la ciencia y la filosofía occidental. El objetivo es, por un lado, que el budismo recupere el terreno perdido en Japón, y por el otro, que se torne una religión atractiva para los occidentales ${ }^{17}$. Es entre los líderes de este movimiento que surgen los primeros misioneros del zen. Por ejemplo, uno de ellos es Soen Shaku, disertante en el I Parlamento Mundial de las Religiones (Chicago, 1893), quien envió a dos de sus discípulos a Estados Unidos, donde abrieron el primer centro zen para occidentales en el año 1905. Otro discípulo de Shaku, Daisetsu T. Suzuki, se convirtió a mediados del siglo XX en el gran introductor del zen en Occidente. A través de sus libros y conferencias, Suzuki influenció directa o indirectamente a la mayoría de los occidentales interesados en esta escuela budista. Sin embargo, el zen que Suzuki -formado intelectualmente en Occidente- presentó allende el Japón, es una versión extremadamente reducida e idealizada de la tradición

${ }^{15}$ Ver al respecto Baumann, (2002).

${ }^{16}$ Ver McMahan (2002) y Pereira (2007).

${ }^{17}$ Este fenómeno es parte de un movimiento más amplio, el llamado "modernismo budista" (cfr. Freiberger, 2001; Baumann, 2002).

Debates do NER, Porto Alegre, ano io, N. I6, P. 49-70, Jul./Dez. 2009 
oriental, sintonizada con los valores de la modernidad para el consumo occidental (Pereira, 2007).

De modo que la difusión del zen en Occidente, más que la irradiación unidireccional de un conjunto de representaciones y prácticas desde el Japón hacia el resto del mundo, puede observarse como un proceso dialéctico, donde el impacto de la modernidad occidental reformó o reconfiguró el zen japonés que luego sería conocido en Occidente. En otras palabras, podemos decir, al igual que Silva da Silveira (2005) al explorar la globalización del neo-hinduismo, que en cuestiones religiosas no sólo existe un Occidente orientalizado, sino también un Oriente occidentalizado, los cuales constituyen los extremos de una vía de doble mano por la cual circulan ideas, conceptos y prácticas espirituales.

Refiriéndonos en particular a nuestro campo fenoménico, muchos de los maestros japoneses que han jugado algún papel en el zen argentino son monjes profundamente reformistas. Daigyo Moriyama y Ryotan Tokuda son maestros críticos del zen tradicional (ver Rocha 2000), al igual que el fallecido Taisen Deshimaru (Koné, 2001) y su discípulo Stéphane Thibaut. Robert Aitken, el fundador de la Diamond Sangha en la cual estudiaron zen Daniel Terragno y Augusto Alcalde, era un discípulo del mencionado maestro heterodoxo Soen Shaku. Por otro lado, si bien Bachoux, Bustamante, Oshiro y Dokyu viajaron a Japón a entrenarse en el zen, es preciso tener en cuenta que fueron a los pocos lugares abiertos a enseñar a occidentales, de modo que estudiaron zen en la periferia del sistema oficial nipón. Sólo Dokyu ingresó al monasterio tradicional más importante del zen soto, el Eiheiji. Esta experiencia hizo del mismo el único maestro misionero en la Argentina reconocido oficialmente por las autoridades de la jerarquía eclesiástica del zen japonés -i.e. la sotoshu.

De modo que, si queremos comprender la dinámica de la recreación del zen en Occidente, es necesario no perder de vista lo siguiente: lo que en esta parte del mundo se conoce como budismo zen es una versión contemporánea e innovadora de esta religión, con reelaboraciones realizadas en su lugar de origen, estrechamente vinculadas al impacto de la modernidad occidental en Japón. A su vez, en cada país de fuera de Asia el zen vive un proceso de reelaboración, de adaptación efectuada sobre cambios previos.

Debates do NER, Porto Alegre, ano io, N. I6, P. 49-70, JUl./Dez. 2009 
Por otra parte, hemos visto que estos monjes reformistas y sus herederos -tanto argentinos como de otros países- pertenecen a comunidades zen trasnacionales, donde no es posible la convivencia continua ni el contacto prolongado entre el maestro y sus discípulos. En este contexto, las relaciones cara a cara no son las únicas que sustentan la identidad colectiva de un centro zen. Nuevas tecnologías de información, especialmente internet, contribuyen a crear y mantener un sentido de pertenencia en comunidades dispersas por varios países y continentes. Las relaciones entre territorio e información en la modernidad son ambiguas, el doble proyecto del sitio web (global) y el templo (local) ejemplifican esta complementariedad entre el uso de los medios tecnológicos más avanzados para la creación de una comunidad virtual y la creación de una base material para el establecimiento de un modo de vida con raíces milenarias, como la convivencia en un templo en un lugar agreste y apartado de las ciudad.

En base a esto distinguimos dos tendencias en el zen argentino: una globalización desde arriba, mediática y virtual, y una localización desde abajo, territorial, fragmentada. En la primera es fundamental el papel de los medios masivos de comunicación, sobre todo en su forma electrónica, para la creación de nuevas clases de "dislocaciones entre las vecindades espaciales materiales y virtuales" (Appadurai, 2001, p. 47), pues la masificación que es consecuencia de la mediatización necesariamente lleva a aglutinar personas y vidas espacialmente alejadas. Estos paisajes mediáticos construyen memorias a partir de la conectividad, son lugares de atravesamiento, lugares de encuentro de significados. Y en la segunda tendencia, juega un rol de primera magnitud la generación de las condiciones de posibilidad materiales de un espacio que permita, aunque sea periódicamente, volver a aglutinar la comunidad religiosa en un ámbito ritualmente estructurado, pensado para el encuentro intersubjetivo y la práctica compartida.

Para concluir podemos decir, en términos de Appadurai (2001), que el flujo cultural zen circula primero por los paisajes mediáticos -libros e internet- más que por el paisaje étnico, pero luego se sustenta en base a un flujo de personas, relaciones sociales e interacciones cara a cara que atraviesan las fronteras nacionales. ¿Podemos hablar de desterritorialización del zen? Lo

Debates do NER, Porto Alegre, Ano io, N. I6, P. 49-70, JUl./Dez. 2009 
que hemos visto hasta aquí nos lleva a pensar que la cuestión fundamental, más que la pérdida del territorio, es la multidimensionalidad del mismo. El sitio web como territorio virtual, el templo como territorio material no pueden ser pensados separadamente. Cada uno tiene sus funciones, sus objetivos y es difícil pensar a cualquiera de ellos sin el otro. Además de esta multidimensionalidad del territorio, podemos hablar de la expansión del mismo hasta que alcanza dimensiones globales. Por ejemplo, los dojos del maestro Stéphane Thibaut, dispersos por toda Europa y Latinoamérica, son altamente localizados, homogéneos y centrados en una comunidad. Y al tiempo que las identidades coproducidas transnacionalmente por las comunidades de práctica zen argentinas superan la fragmentación geográfica, establecen barreras con otros grupos de la misma localidad, aunque todos son budistas zen y la cosmovisión es similar. Dispersas pero unidas, comunidades imaginadas como redes extensas, complejas, estacionalmente aglomeradas, cotidianamente dispersas, comunidades de sentimiento y de práctica íntimas -pese a heterogeneidades nacionales, lingüísticas y generacionales- con una fuerte homogeneidad ideológica y con un ethos compartido que genera habitats de significados simultáneamente globales y locales.

\section{REFERENCIAS BIBLIOGRAFICAS}

ALVES, Daniel. Notas sobre a condição do praticante budista. Debates do NER, Porto Alegre, ano 7, n. 9, p. 57-80, 2006.

ANDERSON, Benedict. Comunidades Imaginadas: Reflexiones sobre el origen y la difusión del nacionalismo. México: Fondo de Cultura Económica, 1983.

APPADURAI, Arjun. La modernidad desbordada: dimensiones culturales de la globalización. Buenos Aires: Fondo de Cultura Económica, 2001.

APPADURAI, Arjun. Memoria, Archivo y Aspiraciones. In: GUTMAN, Margarita (ed.). Construir Bicentenarios: Argentina. Buenos Aires: Observatorio Argentina, 2005. p. 129-135.

BAUMANN, Martin. Global Buddhism: Developmental Periods, Regional Histories, and a New Analytical Perspective. Journal of Global Buddhism, año 2, n. 2, p. 1-43, 2001.

Debates do NER, Porto Alegre, ano io, N. I6, P. 49-70, JUl./Dez. 2009 
BAUMANN, Martin. Buddhism in Europe: Past, Present, Prospects. In: PREBISH, Charles; BAUMANN, Martin (eds.). Westward Dharma: Buddhism Beyond Asia. California: University of California Press, 2002. p. 85-105.

BAUMANN, Martin; PREBISH, Charles. Introduction: Paying Homage to the Buddha in the West. In: PREBISH, Charles; BAUMANN, Martin (eds.). Westward Dharma: Buddhism Beyond Asia. California: University of California Press, 2002. p. 1-16.

BEYER, Peter. Global Migration and the Selective Remaining of Religions. Horizontes Antropológicos, Porto Alegre, ano 4, n. 8, p. 12-33, 1998.

BIANCHI, Susana. Historia de las religiones en la Argentina: las minorías religiosas. Buenos Aires: Sudamericana, 2004.

CARINI, Catón. Budismo local, budismo global: una recorrida por los grupos zen argentinos. REVER, São Paulo, año 5, n. 3, p. 178-195, 2005.

CARINI, Catón. Estrategias del poder sagrado. La construcción de la jerarquía y la autoridad en el budismo zen argentino. Ciencias Sociales y Religión, Porto Alegre, año 8, n. 8, p. 124-151, 2006.

CARINI, Catón. Ritual y poder en los centros budistas zen argentinos. Horizonte, Minas Gerais, v. 6, n. 11, p. 71-87, 2007.

CARINI, Catón. Etnografía del budismo zen argentino: ritual, cuerpo y poder en la recreación de una religión oriental. Tesis (Maestría en Antropología Social) FLACSO, Buenos Aires, 2009.

CAROZZI, María Julia. Nueva Era y Terapias Alternativas: construyendo significados en el discurso y la interacción. Buenos Aires: EDUCA, 2000.

CARVALHO, José Jorge. Antropologia e Esoterismo: dois contradiscursos da modernidade. Horizontes Antropológicos, ano 4, n. 8, p. 53-71, 1998.

COLEMAN, James. The New Buddhism. New York: Oxford University Press, 2001.

DREYFUS, Hubert. On the Internet. London: Routledge, 2001.

FREIBERGER, Oliver. The Meeting of Traditions: Inter-Buddhist and InterReligious Relations in the West. Journal of Global Buddhism, año 2, n. 2, p. 59-71, 2001.

Debates do NER, Porto Alegre, ano io, N. I6, P. 49-70, JUl./Dez. 2009 
GEERTZ, Clifford. La interpretación de las culturas. Barcelona: Gedisa, 1973.

HANNERZ, Ulf. Conexiones trasnacionales: cultura, gente, lugares. Valencia: Frónesis, 1996.

HARVEY, David. Condição Posmoderna. San Pablo: Loyola, 1989.

KONE, Alione. Zen in Europe: A Survey of the Territory. Journal of Global Buddhism, año 2, n. 2, p.139-161, 2001.

KONE, Alione. Le Bouddhisme en Occident: Approches sociologiques et Anthropologiques (Review). Journal of Global Buddhism, año 3, n. 3, p. 92-106, 2002.

LACHS, Stuart. Means of Autorization: Establishing Hierarchy in Ch'an / Zen Buddhism in America. In: AMERICAN ACADEMY OF RELIGION MEETING. Boston, 1999. Disponible en: <http://www.mandala.hr/5/aar.html>.

MADALENA GENZ, Antonio Carlos de. A música silenciosa do Darma: um estudo antropológico das práticas e representaçóes de uma comunidade zen budista em Porto Alegre. Dissertação (Mestrado em Antropologia Social) - PPGAS/UFRGS, Porto Alegre, 2005.

MALLIMACI, Fortunato (coord.) Guia de la diversidad religiosa en Buenos Aires. Buenos Aires: Biblos, 2003.

MATO, Daniel. Des-fetichizar la globalización: basta de reduccionismos, apologías y demonizaciones, mostrar la complejidad y las prácticas de los actores. In: MATO, Daniel (comp.) Estudios latinoamericanos sobre cultura y transformaciones sociales en tiempos de globalización 2. Venezuela: UNESCO-CLACSO, 2001. p. 147-177.

McMAHAN, David. Repackaging Zen for the West. In: PREBISH, Charles; BAUMANN, Martin (eds.). Westward Dharma: Buddhism Beyond Asia. California: University of California Press, 2002. p. 218-229.

MULLEN, Eve. The American occupation of Tibetan Buddhism: Tibetan and their American Host in New York City. Journal of Global Buddhism, año 5, n. 5, p. 85-89, 2004.

NUMRICH, Paul. Old Wisdom in the New World: Americanization in Two Theravada Buddhist Temples. Knoxville: University of Tennessee Press, 1996.

OBADIA, Lionel. Tibetan Buddhism in France: a missionary religion? Journal of Global Buddhism, año 2, n. 2, p. 92-122, 2001.

Debates do NER, Porto Alegre, ano io, N. I6, P. 49-70, JUl./Dez. 2009 
PADGET, Douglas: "Americans Need Something to Sit On" or Zen Meditations Materials and Buddhist Diversity in North America. Journal of Global Buddhism, año 1, n. 1, p. 61-68, 2000.

PEREIRA, Ronan. Religiôes Japonesas no Brasil: seu estudo e situaçâo atual. Newsletter de la Asociación de Cientistas Sociales de la Religión en el Mercosur, Buenos Aires, n. 14, p. 4-14, 2002.

PEREIRA, Ronan A. Una transnacionalización religiosa ignorada: el estudio de las religiones japonesas en Brasil. In: CAROZZI, María Julia; CERIANI CERNADAS, Cesar (coords). Ciencias sociales y religión en América Latina: Perspectivas en debate. Buenos Aires: Biblos, 2007. p. 199-222.

PRESTON, David. The Social Organization of Zen Practice: Constructing Transcultural Reality. Cambridge: Cambridge University Press, 1988.

ROCHA, Cristina. Zen Buddhism in Brazil: Japanese or Brazilian? Journal of Global Buddhism, año1, n. 1, p. 31-55, 2000.

ROCHA, Cristina. Being Zen-Buddhist in the Land of Catholicism. REVER, São Paulo, ano 1, n. 1, p.57-72, 2001.

SAID, Eduard. Orientalismo. Madrid: Debate, 2002

SHOJI, Rafael. Uma perspectiva analítica para os convertidos ao Budismo japonês no Brasil. REVER, São Paulo, ano 2, n. 2, p. 85-111, 2002.

SHOJI, Rafael. Continnum religioso nipo-brasileiro: $\mathrm{O}$ caso do budismo cármico da shingon. Debates do NER, ano 7, n. 9, p. 37-56, 2006.

SILVA DA SILVEIRA, Marcos. New Age \& Neo-Hinduismo: uma via de mão dupla nas relações culturais entre Ocidente e Oriente. Ciencias Sociales y Religión, n. 7, p. 73-101, 2005.

STRAUSS, Sara. Locating yoga. Ethnography and transnational practice. In: AMIT, Vered (ed.) Constructing the Field: Ethnographic Fieldwork in the Contemporary World. London and New York: Routledge, 2000. p. 46-62.

TARDUCCI, Mónica. Fundamentalismo y Relaciones de Género: "Aires de familia" más allá de la diversidad. Ciencias Sociales y Religión, Porto Alegre, año 1, n. 1, p. 189-211, 2000.

Debates do NER, Porto Alegre, ano io, N. I6, P. 49-70, JUl./Dez. 2009 
USARSKI, Frank. O Budismo no Brasil, um resumo sistemático. En: USARSKI, Frank (ed.) O Budismo no Brasil. Saô Paulo: Lorosae, 2002. p. 9-33.

USARSKI, Frank. O momento da pesquisa sobre o budismo no Brasil: Tendencias e questoes abertas. Debates do NER, Porto Alegre, ano 7, n. 9, p. 129-141, 2006.

VELHO, Otávio. Ensaio herético sobre a atualidade da gnose. Horizontes Antropológicos, Porto Alegre, año 4, n. 8, p. 53-71, 1998.

WEBER, Max. Ensayos sobre sociología de la religión: volúmen II. Madrid: Taurus, 1998 [1921]. 